\title{
Los alabastros medievales ingleses y la iconografía jacobea: algunas piezas singulares
}

\author{
Fernando Pérez SuesCun \\ Universidad Complutense de Madrid \\ Departamento de Historia del Arte I (Medieval) / Museo Nacional del Prado \\ fernando.perez@ghis.ucm.es
}

\begin{abstract}
Resumen
A partir del análisis de varias piezas de alabastro conservadas en nuestro país, o que en algún momento han pertenecido a instituciones religiosas o colecciones españolas, se estudia la iconografía del Apóstol Santiago en la vasta producción de alabastros ingleses que tuvo su periodo de esplendor desde mediados del s. XIV hasta las primeras décadas del s. XVI. Se trata de piezas producidas de manera casi industrial, a menudo siguiendo modelos que se repiten con escasas variantes, pero no por ello dejan de ser piezas de gran belleza que despertaron el interés de devotos y coleccionistas en el pasado y lo siguen haciendo hoy día.
\end{abstract}

Palabras clave: Alabastros medievales ingleses, Santiago el Mayor, iconografía jacobea, peregrinación, Ascensión

\section{Medieval English Alabasters and Jacobean Iconography: Some Singular Works}

\begin{abstract}
In this paper some items made in alabaster will be analyzed in order to review the iconography of the Apostle St. James the Greater. Most of these artworks have been kept in religious institutions or Spanish collections but they were made in England, during a period of splendor that took place from mid $14^{\text {th }}$ century to the first decades of the $16^{\text {th }}$ century. These pieces were made in a production line style, so they often repeat the same models, with very few differences. Even so, they are pieces of great beauty which were very appreciated by devotees and collectors in the past and still today.
\end{abstract}

Key words: English Medieval Alabasters, St. James the Greater, Jacobean Iconography, Pilgrimage, Ascension 
La producción inglesa de esculturas de alabastro durante los siglos XIV a XVI es uno de los capítulos más interesantes del desarrollo de las artes decorativas en la Europa medieval. Importantes talleres produjeron sepulcros, figuras de bulto redondo y, especialmente, trípticos y retablos, que no solo tuvieron como destino iglesias y abadías inglesas, sino que también se exportaron a todo el continente europeo. Además el tráfico de este tipo de piezas se vio incrementado por el edicto inglés de prohibición de imágenes religiosas, entre las que se menciona de forma específica los alabastros, y por la furia iconoclasta surgida a partir de la Reforma, que llevó a esconder muchas piezas o a sacarlas del país.

En los primeros años del s. XX comenzaron a organizarse exposiciones monográficas dedicadas a los alabastros medievales ingleses, como la celebrada en 1910 en la Sociedad de Anticuarios de Londres ${ }^{1}$, y se inició la gestación de algunas de las principales colecciones de piezas medievales de alabastro, como las de Philip Nelson, William Burrell ${ }^{2}$ y Walter Leo Hildburgh ${ }^{3}$, entre otros. El propio Hildburgh figura entre los principales estudiosos ${ }^{4}$ del tema, ya que no solo se dedicó a coleccionar alabastros, sino también a estudiar su origen, sus peculiaridades iconográficas o su relación con el teatro. Pero, sin duda, el principal experto en la materia -y referencia obligada para todas las publicaciones dedicadas a los alabastros medievales ingleses- ha sido Francis Cheetham, director del Museo del Castillo de Nottingham y posteriormente de los Museos de Norwich, autor de numerosos artículos y de algunas de las principales monografías sobre el tema, que vieron la luz en 1984, 2001 y $2003^{5}$. Siguiendo su estela, cabría señalar algunas destacadas aportaciones al tema como las realizadas por Ramsay $^{6}$, Williamson ${ }^{7}$ y Prigent ${ }^{8}$, entre otros.

En España se conserva un importante número de piezas inglesas de alabastro, con una distribución geográfica que no se limita a la cornisa cantábrica -la zona más cercana a Inglaterra, donde se supone que sería mayor la afluencia de mercaderes ingleses- sino que se extiende por todo el territorio peninsular, llegando incluso a las Islas Canarias.

1 Illustrated catalogue of the exhibition of English medieval alabaster work: held in the rooms of the Society of Antiquaries, 26 th May to 30 June, 1910, Londres, 1913. Contiene dos interesantes estudios de W.H. St John Hope y E.S. Prior, destacados expertos en el tema.

2 Llegó a reunir más de 100 piezas. W. ANDERSON, "Re-discovery, collecting and display of English medieval alabasters", Journal of the History of Collections, 16, 1 (2004), pp. 47-58, esp. p. 53.

3 En 1946, con motivo de su setenta cumpleaños, donó 270 alabastros al Victoria and Albert Museum (V\&A). C. OAKES, "Dr Hildburgh and the English medieval alabaster", Journal of the History of Collections, 18, 1 (2006), pp. 71-83, esp. p. 80.

4 Entre 1916 y 1955 publicó 34 artículos sobre alabastros. Ibid., p. 78.

5 F. CHEETHAM, English medieval alabasters. With a catalogue of the collection in the Victoria and Albert Museum, Oxford, 1984; The Alabaster Men: Sacred Images From Medieval England, Londres, 2001; Alabaster Images of Medieval England, Londres, 2003.

6 N. RAMSAY, "La production et exportation des albâtres anglais médiévaux", X. BARRAL I ALTET (ed.), Artistes, artisans et production artistique au Moyen Age. III. Fabrication et consommation de l'œuvre, París, 1990, pp. 609-617.

7 P. WILLIAMSON, Object of Devotion: Medieval English Alabaster Sculpture from the Victoria and Albert Museum, Londres, 2010. Es el catálogo de una exposición itinerante que ha tenido ya numerosas sedes internacionales.

8 C. PRIGENT, Les sculptures anglaises d'albâtre au musée national du Moyen Âge Thermes de Cluny, París, 1998. 
Los primeros estudios sobre la presencia de alabastros ingleses en nuestro país fueron realizados en 1956 por Jesús Hernández Perera, que en 1958 y 1970 volvió a tratar el tema, ampliando la lista de obras conocidas ${ }^{9}$. Poco después Santiago Alcolea ${ }^{10}$ planteaba ya una catalogación sistemática de las piezas conservadas, relación que fue ampliada por Joaquín Yarza ${ }^{11}$ haciéndose eco de las nuevas piezas que habían ido dándose a conocer a través de publicaciones centradas únicamente en la presentación de nuevas piezas y su análisis iconográfico. El artículo del profesor Yarza puede ser considerado como el punto de partida de los estudios orientados a analizar el tema de los intercambios comerciales entre Inglaterra y la Península Ibérica -fundamentalmente Castilla- y la importación de alabastros ingleses, destacando, entre otros, las aportaciones de Javier Martínez de Aguirre ${ }^{12}$, Olga Pérez Monzón ${ }^{13}$ y, especialmente, Ángela Franco Mata ${ }^{14}$.

Planteamos aquí un estudio sobre las abundantes piezas alabastrinas de temática jacobea que han llegado hasta nuestros días, que debe comenzar, indudablemente, por el retablo ${ }^{15}$ dedicado a la vida de Santiago que el 25 de mayo de $1456^{16}$ fue donado a la catedral de Santiago por el clérigo inglés John Goodyear ${ }^{17}$, tal y como aparece recogido en el Tumbo $F$ (fol. $2 \mathrm{v}$.) del archivo compostelano ${ }^{18}$. Se trata de una pieza muy singular $^{19}$, ya que incluye algunas escenas poco habituales en la iconografía de carácter

9 J. HERNÁNDEZ PERERA, "Un alabastro gótico inglés”, Archivo Español de Arte, XXIX (1956), pp. 302-305; "Alabastros ingleses en España”, Goya, 22 (1958), pp. 216-222; "Más relieves ingleses góticos de alabastro en España”, Homenaje a Elías Serra Rafols, II, La Laguna, 1970, pp. 251-264.

10 S. ALCOLEA, "Relieves ingleses de alabastro en España: ensayo de catalogación", Archivo Español de Arte, XLIV (1971), pp. 137-154.

11 J. YARZA LUACES, “Alabastros esculpidos y comercio Inglaterra-Corona de Castilla en la Baja Edad Media”, Homenaje al profesor Hernández Perera, Madrid, 1992, pp. 605-617.

12 J. MARTÍNEZ DE AGUIRRE, "Mercaderes y arte gótico en las villas marineras del reino de Castilla", Santander y Cantabria en la Conquista de Sevilla. 750 Aniversario, Santander, 1999, pp. 79-110, y "Notas sobre la importación de obras escultóricas en la Castilla bajomedieval", Actas del Congreso Internacional sobre Gil Siloe y la escultura de su época, Burgos, 2001, pp. 367-380, esp. pp. 371-374.

13 O. PÉREZ MONZÓN, "Producción artística en la Baja Edad Media. Originalidad y/o copia", M.V. CHICO PICAZA, L. FERNÁNDEZ FERNÁNDEZ y M. MIQUEL JUAN (eds.), El siglo XV hispano y la diversidad de las artes, $\mathrm{n}^{\circ}$ especial de Anales de Historia del Arte, 22 (2012), pp. 85-121, esp. pp. 91-94.

14 Considerada como la principal autoridad en el estudio de los alabastros ingleses en España, a los que ha dedicado números artículos, en 1999 publicó la única monografía existente en España sobre ese tema: A. FRANCO MATA, El retablo gótico de Cartagena y los alabastros ingleses en España, Murcia, 1999.

15 Mide 186 × $90 \mathrm{~cm}$ (58 x 27 la pieza central y 41 x 27 las cuatro restantes), y conserva gran parte de la mazonería original de madera. Forma parte de las colecciones del Museo de la Catedral de Santiago.

16 La fecha de donación, 1456, marca una data ante quem para su ejecución y constituye el único testimonio documental para la datación de todo la producción inglesa de alabastros.

17 Al parecer era el rector de la iglesia Chale (antes Cheil) en la Isla de Wight, diócesis de Winchester, según W.L. HILDBURGH, "A Datable English Alabaster Altarpiece at Santiago de Compostela", Antiquaries Journal, 6 (1926), pp. 304-307.

18 A. LÓPEZ FERREIRO, "Recibo del retablo de Santiago que trajo el Cura inglés Juan Gudgar", Historia de la Santa A.M. Iglesia de Santiago, vol. VIII, Santiago de Compostela, 1905, ap. XXIX, p. 112.

19 Como tal ha figurado en varias exposiciones de temática jacobea, donde ha sido estudiada por diversos autores: A.G. BARRAL, "Retablillo inglés de John Goodyear", Galicia no Tempo, Santiago de Compostela, 1990, pp. 209-210; J. CARRO OTERO, "Retábulo Goodyear", A Catedral de Santiago e o seu Património Cultural. Paradigmas da Arte Europeia, Braga, 1993; S. MORALEJO, "Retablo de la vida de Santiago ofrecido por John Goodyear", Santiago, camino de Europa. Culto y cultura en la peregrinación a Compostela, Santiago de Compostela, 1993, pp. 506-507; R. IZQUIERDO PEIRÓ, "Retablo con escenas de la vida del Apóstol Santiago", Domus Iacobi, Santiago de Compostela, 2011, pp. 8-9; y "Santiago el Mayor en las 
jacobeo y además no se conocen más ejemplos de altares en alabastro dedicados al "hijo del trueno". Cada escena va acompañada de una inscripción que identificada el episodio representado. Así, la primera, en el extremo izquierdo, narra la vocación de Santiago y su hermano Juan: Vocatio Iacobi ad Apostolatum. Mientras sujetan las redes, los dos hijos del Zebedeo -también presente en la escena, en el extremo derecho de la barca- escuchan atentamente las palabras que Cristo les dirige desde la orilla, que estarían recogidas en la filacteria que flamea sobre sus cabezas. Santiago ya aparece caracterizado como peregrino ${ }^{20}$, vistiendo un manto de viaje y con la cabeza cubierta por un sombrero de ala vuelta decorado con una concha en su parte frontal. A continuación se representa la aparición de Cristo resucitado a sus discípulos para enviarles a predicar el evangelio: Missio Iacobi ad predicandam fidem. Con una organización que recuerda a la escena del Descenso a los Infiernos, Jesucristo, cubierto únicamente con un manto y sujetando la cruz de palo largo símbolo de triunfo sobre la muerte, se dirige al colegio apostólico, organizado en tres niveles o alturas. Santiago es, lógicamente, el más próximo a él y, además del sombrero que ya lucía en la escena anterior, lleva un zurrón en el costado izquierdo -también decorado con una concha, como el sombrero- y un bordón de caminante - con puntera metálica en la parte inferior y pomo en la superior-; viste traje corto y va descalzo, y tras él se encuentran San Juan Evangelista -con la palma-, San Pedro -con la llave- y otro apóstol imberbe que, como el resto, carece de atributo identificativo. La escena central muestra la predicación del Apóstol desde un púlpito: Praedicatio Sancti Iacobi ${ }^{21}$. Situado por encima del público que escucha sus palabras -aunque la mayoría de los presentes no parecen prestarle demasiada atención y están ocupados en hablar entre ellos ${ }^{22}$, su mensaje es recogido en la serpenteante

colecciones del Museo Catedral”, Iacobus, Santiago de Compostela, 2013, pp. 48-62, esp. pp. 50-52. Pieza de casi obligada reproducción en todo tipo de publicaciones relacionadas con el Camino de Santiago, también ha sido objeto de una especial atención en los estudios centrados en el análisis de la iconografía jacobea en la catedral compostelana: R. YZQUIERDO PERRÍN, "Historiografía e iconografía de Santiago en la Catedral Compostelana", D. ESTEFANÍA y A. POCIÑA(eds.), Géneros literarios romanos. Aproximación a su estudio, Madrid, 1996, pp. 1-52, y "Textos e iconografías: Vita, Missio, Passio y Translatio de Santiago Zebedeo", Abrente, 44 (2012), pp. 9-40; J.M. GARCÍA IGLESIAS, "Sobre la iconografía de Santiago el Mayor en su Catedral de Compostela", Cuadernos de la Cátedra de Patrimonio y Arte Navarro, 5 (2011), pp. 47-78.

20 Es muy abundante la bibliografía que estudia el tema de la iconografía del Apóstol Santiago, sus atributos y tipos iconográficos. Únicamente citaremos, a modo de ejemplo, algunos de los estudios generales más interesantes: I.G. BANGO TORVISO, "Santiago Peregrino", Santiago. La Esperanza (Xacobeo 99), Santiago de Compostela, 1999, pp. 89-97; J. FERNÁNDEZ ARENAS, Elementos simbólicos de la peregrinación jacobea, León, 1998; H. JACOMET, "Iconografía de Santiago", Santiago el Mayor y la Leyenda Dorada (Xacobeo 99), La Coruña, 1999, pp. 27-34; J.K. STEPPE, "L'iconographie de Saint-Jacques le Majeur (Santiago)", Santiago de Compostela. 1000 ans de Pèlerinage Européen (Europalia 85), Gante, 1985, pp. 129-153; L. VÁZQUEZ DE PARGA, J.M. LACARRA y J. URÍA RÍU, "La Iconografía de Santiago y la Peregrinación”, Las Peregrinaciones a Santiago de Compostela, t. I, Madrid, 1948, pp. 565-573.

21 Una escena similar, posiblemente de origen francés, se conserva en las colecciones del Victoria \& Albert Museum (A123-1946). Mide 43,5 x $29 \mathrm{~cm}$ y se fecha a fines del s. XV. En realidad no existe certeza de que se trate de Santiago el Mayor como sugiere Cheetham (op. cit., 1984, p. 335), y también se ha propuesto su identificación con Cristo en el sermón de la montaña (Illustrated catalogue..., op. cit., 1913, no 45, p. 63). Se trata de un personaje barbado, con nimbo, que desde lo alto de un púlpito se dirige a un grupo integrado por cinco hombres y dos mujeres.

22 Son tres mujeres y siete hombres, que se han puesto en relación con los Siete Varones Apostólicos que, según la tradición, acompañaron al Apóstol en su labor evangelizadora por Hispania. J.M. GARCÍA IGLESIAS, op. cit. (2011), p. 56, nota 59. 
filacteria -cuya inscripción está casi totalmente desaparecida- que oculta parcialmente el árbol de la parte superior, que sitúa la escena en un exterior. La cuarta escena recoge la muerte de Santiago por orden del rey Herodes: Martirium Sancti Iacobi. El monarca, situado en el lado derecho, sentado con las piernas cruzadas - postura o actitud asociada a la idea de majestad, lo mismo que el estrado a sus pies- contempla cómo el Apóstol -arrodillado- ya ha sido decapitado por el sayón situado a su espalda, que lleva un largo alfanje, y su cabeza ${ }^{23}$ ha caído sobre una bandeja situada bajo é ${ }^{24}$. Por encima del grupo de soldados o consejeros ${ }^{25}$ de Herodes, dos ángeles llevan hacia el cielo el alma de Santiago, representada - como es habitual- bajo la apariencia de una pequeña figura desnuda y con las manos en oración. El ciclo concluye con la representación de la traslación del cuerpo del Apóstol hasta Galicia: Traslatio Sancti Iacobi ad Compostele ${ }^{26}$. Santiago, perfectamente amortajado y con la cabeza aparentemente unida a su cuerpo -pese a haber sido decapitado- es trasladado en una barca guiada por tres ángeles; el del centro dirige su mirada hacia él mientras los otros dos parecen manipular la vela de la embarcación, decorada con dos cruces rojas y muy similar a la que aparece en la escena de la vocación. Dos árboles en primer plano parecen anunciar la inminente llegada a las costas gallegas (Fig. 1).

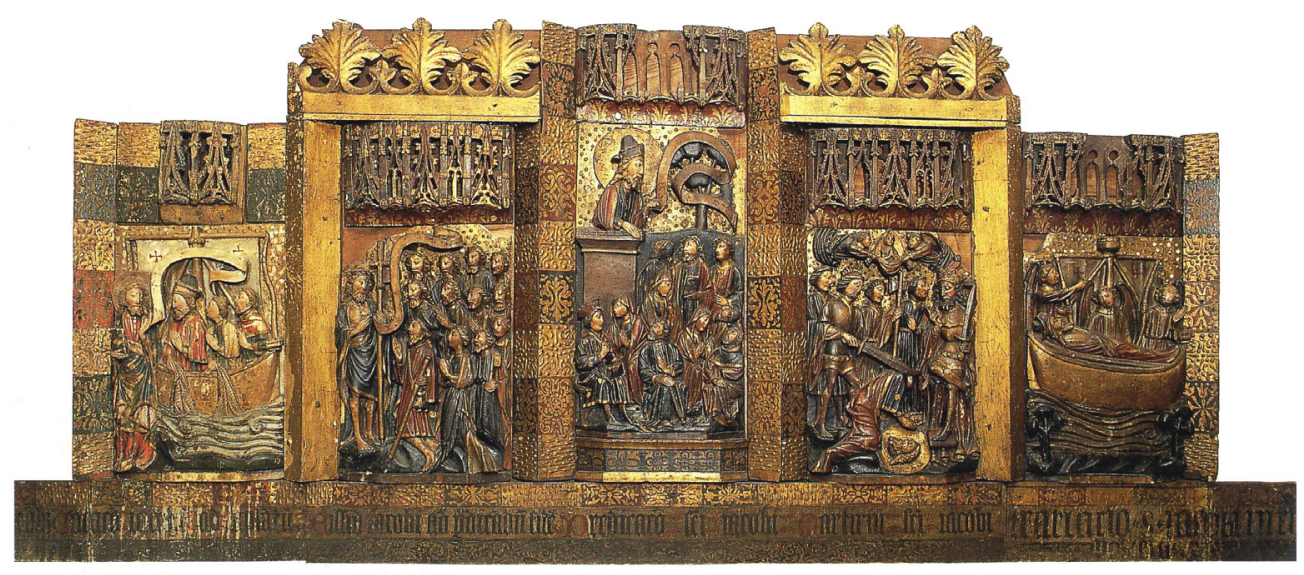

Fig. 1. Retablo de la Vida del apóstol Santiago, de John Goodyear. h. 1456. Alabastro policromado, 186 x $90 \mathrm{~cm}$. Museo de la Catedral, Santiago de Compostela.

23 Es la única escena en la que Santiago, lógicamente, no lleva sombrero

24 Como señala Franco Mata, es un préstamo de las escenas de decapitación de San Juan Bautista. A. FRANCO MATA, "Escultura gótica inglesa en Galicia", Hasta el Confín del Mundo. Diálogos entre Santiago y el Mar (Catálogo de la exposición), Vigo, 2004, pp. 163-173, esp. p. 170.

25 El Profesor Yzquierdo Perrín afirma - creo que erróneamente- que son los discípulos de Santiago que piden a Herodes su cuerpo. R. YZQUIERDO PERRÍN, op. cit., 1996, p. 11, y op. cit., 2012, p. 27.

26 Para el estudio de las obras hispanas de época medieval que recogen este episodio vid. M. MELERO MONEO, "Translatio Santi Jacobi. Contribución al estudio de su iconografía", VI Congreso Español de Historia del Arte. Los Caminos y el Arte, t. III, Santiago de Compostela, 1989, pp. 71-90. 
Además de este altar o retablo dedicado exclusivamente al Apóstol Santiago, podemos encontrar otras representaciones del hijo del Zebedeo en escenas que recogen diversos episodios de la vida de Cristo, fundamentalmente de su Pasión y Resurrección. No se conserva en nuestro país, que yo sepa, ningún alabastro en el que se represente la Última Cena ni tampoco el episodio inmediatamente anterior, el Lavatorio de pies, y en los escasos ejemplares conservados fuera de nuestras fronteras ${ }^{27}$ el apóstol Santiago no puede ser reconocido en ninguna de ellas al no llevar ningún atributo que le diferencie del resto de apóstoles.

Sí contamos con una representación de la Oración en el huerto ${ }^{28}$ que, procedente de la iglesia parroquial de San Esteban de Valcarría, Vivero (Lugo), se conserva actualmente en el Museo Catedralicio y Diocesano de Mondoñedo (Lugo) ${ }^{29}$. Muestra a Cristo arrodillado ante el cáliz de la Pasión situado sobre un pequeño montículo tras el que aparece la cabeza de Dios Padre envuelta por unos rayos luminosos; junto a él se encuentran sus tres discípulos más cercanos, mientras que por el extremo superior derecho, tras una empalizada o cerca de ramas entrelazadas, asoman dos de los soldados que vienen a prenderle. San Juan evangelista, a la derecha de Cristo es reconocible por su rostro imberbe y por llevar la palma ${ }^{30}$, uno de sus principales atributos, vinculado al episodio de la Dormición de la Virgen María en Efeso. A la izquierda, San Pedro - con barba y ligera calvicie- sostiene un libro, mientras que Santiago el Mayor, de mayor tamaño que sus compañeros, está dormido, totalmente echado sobre el suelo; como es habitual en este tipo de escenas, carece de atributos reconocibles y es identificado simplemente por eliminación, ya que San Juan y San Pedro no ofrecen dudas sobre su identificación.

Más problemas ofrece la identificación de Santiago en la placa que representa la Oración en Huerto ${ }^{31}$ y forma parte de las colecciones del Victoria and Albert Museum (V\&A A.69-1946) ${ }^{32}$. Ninguno de los tres apóstoles que acompañan a Cristo lleva atributo que lo identifique, aunque San Juan es reconocible por no llevar barba; suponemos que Santiago es el personaje situado en el ángulo inferior derecho de la composición, ya que habitualmente San Pedro suele ser el más próximo a la figura

27 Cheetham recoge cuatro representaciones del Lavatorio y siete de la Última Cena. F. CHEETHAM, op. cit., 2003, pp. 107-108.

28 Mide 37 × 24 × $6 \mathrm{~cm}$, conserva algunos restos de policromía y se fecha hacia 1450-1475. El altar o ciclo del que formaba parte estaba integrado por siete piezas, algunas de ellas desaparecidas, que representaban los siguientes episodios: Oración en el Huerto y Prendimiento, Cristo ante Pilatos o Juicio de Cristo (perdido), Flagelación (perdido), Cristo con la cruz camino del Calvario, Crucifixión, Descendimiento y Santo Entierro.

29 R. SÁNCHEZ AMEIJEIRAS, "Devociones e imágenes medievales en la provincia eclesiástica de Mondoñedo", Estudios Mindonienses, no 15 (1999), pp. 375-409, esp. pp. 399-404; A. FRANCO MATA, "Nuevos caminos, viejas síntesis (III)", Gallaecia Petrea, catálogo de la exposición, Santiago de Compostela, 2012, pp. 414-417.

30 Es, sin lugar a dudas, su principal atributo en las numerosas piezas inglesas de alabastro en las que aparece -tanto en relieves con escenas de la Crucifixión y la Ascensión como en imágenes de bulto- frente al cáliz con la serpiente, otro de sus principales atributos, con el que prácticamente no es representado en los alabastros medievales ingleses, salvo cuando se trata de imágenes exentas.

31 Cheetham recoge 7 representaciones de la Oración en el huerto. F. CHEETHAM, op. cit., 2003, p. 108.

32 Mide 42,2 x 26,7 cm y se fecha en el s. XV. F. CHEETHAM, op. cit., 1984, p. 223 (cat. 150). Como el resto de alabastros de la colección del Victoria \& Albert Museum, su ficha se encuentra disponible en la web del Museo: http://collections.vam.ac.uk 
de Cristo arrodillado. Lo mismo sucede con el panel conservado en el Museo de la Universidad de Princeton (USA) ${ }^{33}$, donde ninguno de los apóstoles lleva atributo y los tres parecen estar barbados. En cambio, en el panel custodiado en el Musée Thomas Dobrée de Nantes (Francia) ${ }^{34}$, San Pedro, situado en primer plano y tonsurado, lleva una espada -con su correspondiente vaina- que debe ser puesta en relación con el episodio inmediatamente posterior del prendimiento de Cristo, cuando Pedro cortó una oreja a Malco, criado del Sumo Sacerdote; San Juan, imberbe, y Santiago, con barba, carecen de atributos.

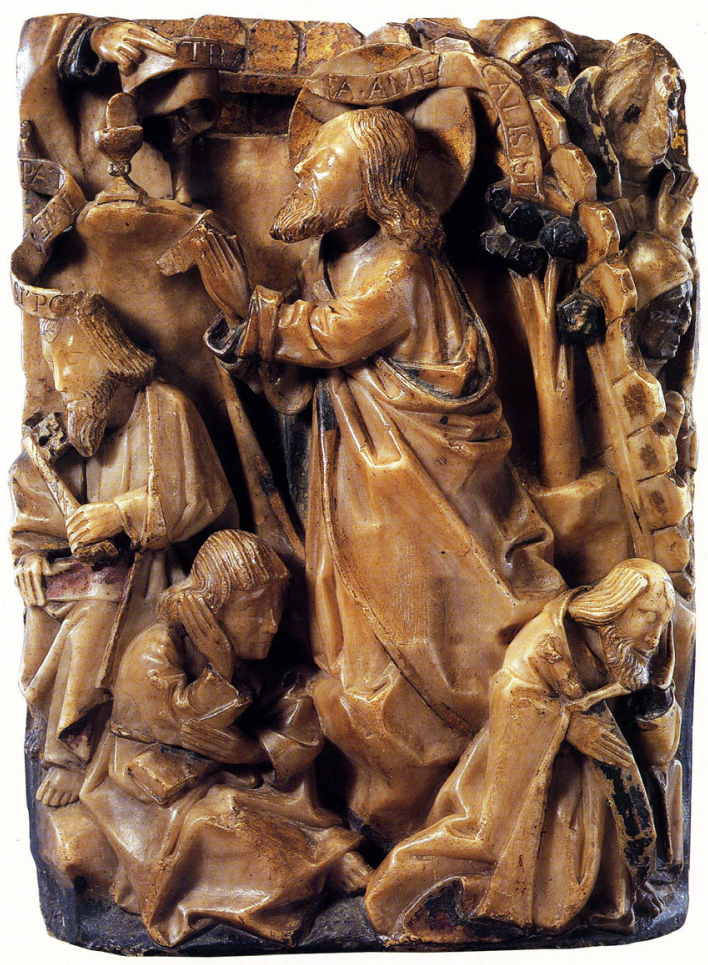

Fig. 2. Oración en el huerto. S. XV. Alabastro policromado. 39 x 27,5 cm. Colección privada, Gran Bretaña.

Mucho más interesante para nuestro estudio es una representación conservada en una colección privada de Gran Bretaña ${ }^{35}$, en la que Cristo arrodillado ante el cáliz recibe la bendición de la Dextera Dei que aparece en el ángulo superior izquierdo de

33 Mide 40 x $19 \mathrm{~cm}$ y se fecha en el s. XV. F. CHEETHAM, op. cit., 2003, p. 108 (nº 2).

34 Mide 50 x $30 \mathrm{~cm}$ y forma parte de un altar dedicado a la Pasión de Cristo, con nueve escenas. F. CHEETHAM, op. cit., 2003, p. $108\left(\mathrm{n}^{\mathrm{o}} 3\right)$, p. $172\left(\mathrm{n}^{\mathrm{o}} 12\right)$ y lám. 13.

35 Fechada en el s. XV, mide 39 x 27,5 cm y fue dada a conocer por F. Cheetham en el catálogo de la exposición The Alabaster Men. Sacred Images from Medieval England, celebrada en la Daniel Katz Gallery (octubre-noviembre 2001), Londres, 2001, pp. 34-35. 
la escena. Una filacteria, parcialmente mutilada, recoge una inscripción en latín con las palabras que Cristo pronunció en esos momentos: Padre, si es posible, aleja de mí este cáliz, mientras que por el lado derecho, tras la empalizada de madera, asoman las cabezas de tres soldados que se disponen a apresar al Señor. Junto a él se encuentran sus discípulos dormidos: San Pedro, con una gran llave en la mano, San Juan, imberbe y con un libro, y Santiago el Mayor con una espada. Es un atributo alusivo a su muerte ${ }^{36}$, decapitado por orden de Herodes, que no es demasiado frecuente en las representaciones del Apóstol, aunque podemos verle con ella en varias portadas francesas del s. XIII ${ }^{37}$ (Fig. 2).

El siguiente episodio de la Vida de Cristo en el que Santiago está presente es la $A s-$ censión del Señor, escena bastante frecuente en la producción inglesa de alabastros ${ }^{38}$ pero de la cual solo se conservan dos ejemplares en España. El primero de ellos es un fragmentado relieve ${ }^{39}$ que se conserva en el Museo San Telmo de San Sebastián/ Donostia $^{40}$, formando parte de un grupo de ocho piezas de alabastro procedentes de la derruida ermita de San Salbatore de Aguirre en Oyarzun/Oiartzun ${ }^{41}$.

La plancha, que ha sido datada a comienzos del s. XV atendiendo al estilo y vestimenta de los personajes ${ }^{42}$, se encuentra fragmentada -en la actualidad mide $30,5 \mathrm{x}$ $24,5 \times 5,50 \mathrm{~cm}-\mathrm{y}$ ha perdido la parte superior, donde se verían los pies de Cristo; hoy solo se conserva la parte superior del montículo desde el que inicia su ascenso al cielo. Como es habitual en los alabastros que representan este episodio, en la parte inferior, en primer plano, se encuentra la Virgen María, coronada y con ricos ropajes, con las manos (desaparecidas) unidas ante el pecho en actitud de oración, y, frente a ella, San Juan, que levanta su mano derecha -en señal de sorpresa- al tiempo que en la izquierda sostiene la palma, colocada hacia abajo, apoyada en el suelo. Tras él está San Judas Tadeo, que lleva una pequeña barca en las manos y levanta también su mano derecha, y en el lado opuesto, detrás de María, se halla Santiago el Mayor, caracterizado como peregrino. Es el único personaje de la escena que lleva traje corto, lo que permite ver sus pies descalzos, y colgado a su espalda, sobre los hombros, tiene un gran sombrero de ala ancha; en la mano derecha sostiene el bordón de cami-

36 Recientemente el Museo Nacional del Prado adquirió una tabla francesa de comienzos del s. XV, hacia 1405-1408, que representa La Oración en el huerto con el donante Luis I de Orleans, en la que los tres apóstoles que acompañan a Cristo llevan los mismos atributos: San Pedro la llave, San Juan el libro y Santiago la espada, pero -erróneamente- se afirma que alude a su condición de caballero. P. SILVA MAROTO, La Oración en el huerto. Una tabla francesa descubierta, Madrid, 2013.

37 Portada sur de Chartres, portada occidental de Amiens, portada norte de Reims, portada de Le Mans... E. MÂLE, L'Art Religieux du XIII' siècle en France, París, 1958, p. 313 (cuadro).

38 Cheetham recoge 46 representaciones. F. CHEETHAM, op. cit., 2003, pp. 107-108.

39 Tradicionalmente considerado simplemente como "grupo", en el año 1999 planteé la hipótesis de que representaba el episodio de la Ascensión, teoría que fue recogida y aceptada por la Dra. Franco Mata. A. FRANCO MATA, op. cit., 1999, pp. 48 y 90 (Fig. 58).

$40 \mathrm{~N}^{\mathrm{o}}$ Inv. P-2472. Agradezco a Arantxa Barandiaran, responsable de colecciones del Museo, su ayuda a la hora de conseguir imágenes de estas piezas y sus correspondientes fichas de Inventario.

41 P.M. SORALUCE y A. ARZÁC, “Arqueología guipuzcoana”, Euskal-Herria, XXIX (1893), pp. 331337, 365-372 y 392-401, esp. pp. 367 y 368; G. MANSO DE ZÚNIGA, Catálogo del Museo de San Telmo, Bilbao, 1976, p. 79; y X. MARTIARENA LASA, "Los alabastros ingleses en Gipuzkoa: Nuevas aportaciones en la franja costera", Ars Bilduma, 3 (2013), pp. 151-166, esp. pp. 154-155 (Fig. 3)

42 X. MARTIARENA LASA, op. cit., 2013, p. 154. 
nante. Detrás de él -y también de San Judas Tadeo- se ven las manos de otros apóstoles - desaparecidos-, conservándose únicamente la figura "completa" de un apóstol justo encima de María y el torso de otro más sobre la figura de San Juan (Fig. 3).

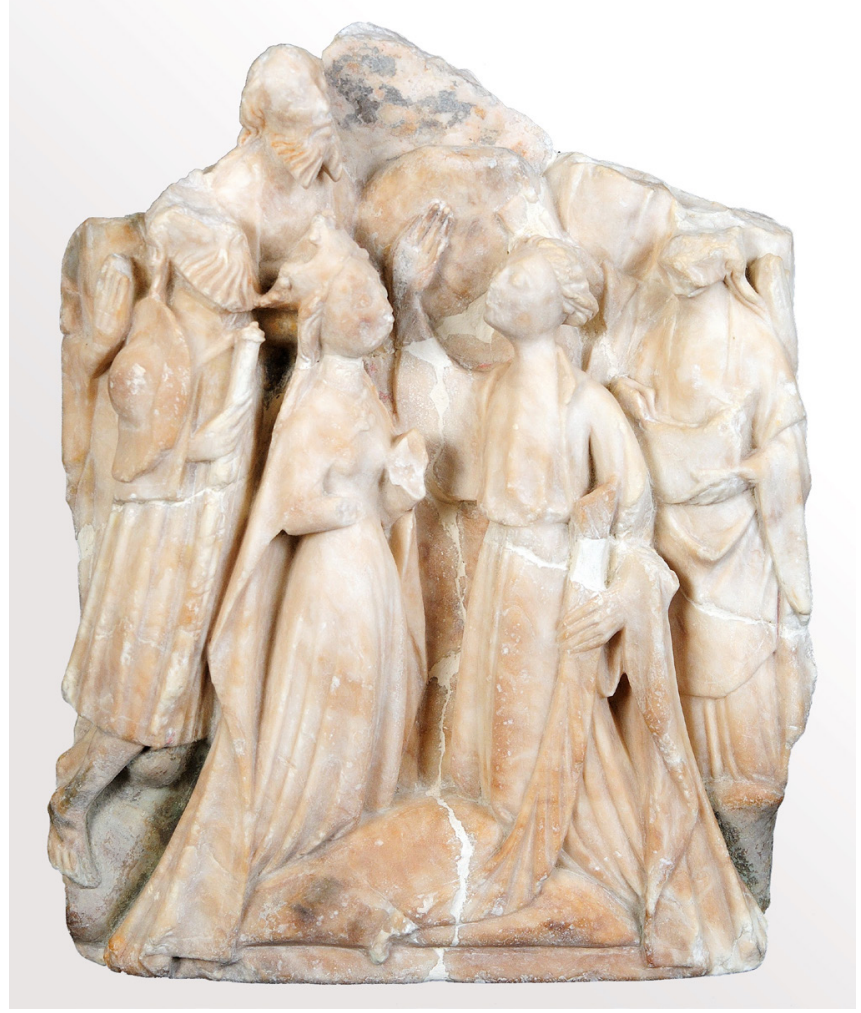

Fig. 3. Ascensión. Comienzos del s. XV. Alabastro policromado. 30,5 x 24,5 cm. Museo San Telmo, San Sebastián/Donostia.

En estos momentos, en el Convento de las Madres Agustinas de Rentería/Errenteria se conserva una placa de alabastro que representa también la Ascensión y que procede del clausurado convento de las Madres Agustinas de Durango, aunque su origen se remonta al convento agustino de la Esperanza de Bilbao ${ }^{43}$. Ese relieve, que mide 43 × $28 \mathrm{~cm}$ y presenta policromía -aunque posiblemente sea un repinte moderno-, está completo y permite ver cómo la figura de Cristo -solo se ve la parte inferior de su cuerpo, a partir de las rodillas- parece entrar en una nube, recurso tradicional para representar su Ascensión. Alrededor del montículo, se distribuyen doce figuras,

43 Aunque se especuló con la posibilidad de que regresase a la diócesis de Bilbao (X. MARTIARENA LASA, op. cit., 2003, pp. 161-162), la Madre Superiora del Convento nos confirmó (13/9/2013) que de momento la pieza seguiría en Errenteria. Agradezco asimismo las facilidades que posteriormente (4/3/2014) nos dio para estudiar y fotografiar la pieza, actualmente expuesta en el refectorio de la comunidad. 
la Virgen María y once de sus discípulos. Como en el relieve del Museo de San Telmo, la Virgen coronada y San Juan con la palma -aquí con las dos manos unidas en oración- ocupan los lugares preferentes, encabezando los dos grupos de figuras y seguidos por San Pedro con la llave y San Andrés con la cruz en aspa, respectivamente. Santiago ha perdido, por tanto, su lugar preferente, convirtiéndose en uno más de los apóstoles, sin ningún atributo que lo identifique.

Gracias a las fotografias y referencias que Cheetham incluye en sus numerosas publicaciones sobre los alabastros medievales ingleses, podemos relacionar o comparar estas dos representaciones de la Ascensión conservadas en España con otros ejemplares existentes en diferentes museos o instituciones religiosas.

A excepción de alguna pieza, como V\&A A.113-1946 usurpado el lugar preferente que San Juan ocupa frente a la Virgen María, relegando a este a un lugar secundario, tras é $1^{45}$, en la práctica totalidad de paneles de alabastros que representan el episodio de la Ascensión, los puestos principales -en primer plano y en el centro de la composición- suelen estar ocupados por María y por San Juan. En algunos ejemplares -Museo Estatal de Trier (Alemania) ${ }^{46}$ y Priorato de Workington, en Cumbria (Gran Bretaña) ${ }^{47}$-, ninguno de los protagonistas lleva su atributo, y en piezas como la V\&A A.27-19508, solo la madre de Jesús y su discípulo amado -con la palma- pueden ser identificados, ya que el resto de los apóstoles no lleva ningún atributo. Pero lo habitual es que varios de ellos sí los lleven, como ocurre, por ejemplo, en la V\&A A.147-1946 ${ }^{49}$, donde San Andrés está situado detrás de María y es reconocible por llevar una pequeña cruz en aspa, el instrumento de su martirio, mientras que detrás de San Juan - con palma- se reconoce a San Pedro con una -mutiladallave y a San Bartolomé que sostiene el cuchillo con el que fue desollado. En el panel conservado en el Museo Nacional de Copenhague ${ }^{50}$, detrás de la Virgen María está San Pedro -tonsurado y con una gran llave doble en las manos-, y San Judas -que lleva una barca- se sitúa tras San Juan, que porta la tradicional palma, mientras que el resto de apóstoles carece de atributo, como también ocurre en la pieza conservada en una colección privada de Basilea, donde solo San Juan -con la palma- y San Judas -con una barca en las manos y situado inmediatamente detrás de él- llevan atributos.

En el Altar de Munkathverá (Islandia), conservado en el Museo Nacional de Copenhague ${ }^{51}$, el primer plano de la composición está ocupado, de izquierda a derecha, por San Bartolomé (cuchillo), San Pedro (llave), la Virgen María, San Juan (palma), San Andrés (cruz en aspa) y San Simón (gran concha).

\footnotetext{
44 Mide 47,5 x 36,7 cm y se fecha en el s. XV. F. CHEETHAM, op. cit., 1984, p. 291 (cat. 218).

45 Ninguno de ellos lleva atributo, reconociéndose por sus habituales características físicas: San Pedro está tonsurado y San Juan es el único que no tiene barba.

46 En 1938 estaba en el Museo, pero posteriormente se perdió su pista. F. CHEETHAM, op. cit., 2003, p. $142\left(n^{\circ} 13\right)$ y lám. 92.

47 Mide 40,6 x 25,4 cm. F. CHEETHAM, op. cit., 2003, p. 142 (nº 20) y lám. 94.

48 Mide 40,8 x 30,2 cm y se fecha a fines del s. XIV. F. CHEETHAM, op. cit., 1984, p. 288 (cat. 215).

49 Mide 31,1 x 27,1 cm y se fecha a fines del s. XIV. Ibid., p. 289 (cat. 216).

50 F. CHEETHAM, op. cit., 2003, p. 142 (n 16).

51 Mide 70,5 x 177,5 cm. Ibid., p. $142\left(\mathrm{n}^{\circ} 15\right)$ y p. $167\left(\mathrm{n}^{\circ} 16\right)$.
} 
Por último, en el panel conservado en el Museo Municipal de Bristol ${ }^{52}$ solo San Juan y San Judas, situado inmediatamente tras él, llevan atributo -la palma y la barca, respectivamente-, aunque en el extremo izquierdo, tras la figura de María, aparece una figura vestida con un traje corto, que podríamos identificar -tanto por la indumentaria como por la posición- como Santiago el Mayor caracterizado de peregrino.

A partir del s. XV la figura del apóstol Santiago el Mayor empieza a cobrar un especial protagonismo en las representaciones de la Ascensión, ocupando un lugar preferente -siempre detrás de María- y luciendo una indumentaria que permite reconocer en él a un peregrino, como es característico de la iconografía jacobea sobre todo tipo de soporte, ya sea relieves, esculturas exentas, pinturas, tapices, miniaturas...

En un panel de alabastro que hoy forma parte de un pequeño altar portátil, montado en el s. XVII, con la Crucifixión y la Ascensión pintadas en las puertas de madera (V\&A A.112-1946) ${ }^{53}$, son San Pedro, con la llave bajo el brazo derecho, y su hermano San Andrés, con una gran cruz aspada, los que ocupan los lugares principales, mientras que la Virgen y San Juan aparecen en la misma posición pero en un segundo plano. Detrás de San Pedro se encuentra Santiago el Mayor, barbado como siempre y cubriéndose la cabeza con un sombrero cónico decorado en su parte frontal con una concha; con la mano izquierda sujeta un libro cerrado y en la derecha empuña un bordón corto. Tras él hay otro apóstol sin atributo identificador y justo encima otro que lleva una especie de bollo de pan - ¿San Felipe?-. Detrás de San Andrés se sitúa San Judas, con una pequeña barca, y después San Simón, que sujeta una enorme concha.

Muy similar a esta es la placa conservada en el Colección Burell de Glasgow, procedente de la Abadía de Marolles ${ }^{54}$. Santiago está detrás de San Pedro -que lleva la llave bajo el brazo-, sujeta el bordón con su mano derecha y se cubre la cabeza con un gorro cónico, que en esta ocasión no lleva la concha en su parte frontal. San Andrés y San Simón ocupan el mismo lugar que en la obra del V\&A y llevan los mismos atributos -cruz en aspa y gran concha, respectivamente- mientras que el apóstol situado entre ellos lleva un objeto que recuerda a la palma que suele llevar San Juan en esta escena $^{55}$. Al fondo, otros dos apóstoles llevan un hacha y una lanza.

En el denominado "Altar Swansea" (V\&A A.89-1919) ${ }^{56}$, dedicado a los gozos de María, uno de los cinco paneles narrativos representa la Ascensión de Cristo, con la Virgen María y San Juan ocupando los puestos de honor. Tras ellos, Santiago el

52 Mide 50 × $26 \mathrm{~cm}$, y posiblemente la parte superior del cuerpo de Cristo sea un añadido posterior. Ibid., p. $142\left(n^{\circ} 11\right)$ y lám. 90.

53 Mide 49,2 x $34 \mathrm{~cm}$ y se fecha a comienzos del s. XV, hacia 1400-1425. F. CHEETHAM, op. cit., 1984, p. 290 (cat. 217).

54 Mide 41,3 x 27,3 cm y debe fecharse a comienzos del s. XV. F. CHEETHAM, op. cit., 2003, p. 142. Imagen en http://boppardconservationproject.wordpress.com/tag/chasuble/

55 No puede ser él, porque aparece en segundo plano, justo encima de San Andrés, pero tampoco recuerda a una cimitarra, que podría ser otro de los atributos de San Judas Tadeo. Nos encontramos, por tanto, ante un problema de identificación iconográfica por parte del artífice de la pieza.

56 Mide 42 x 26,6 cm y se fecha en la segunda mitad del s. XV, hacia 1460-1490. F. CHEETHAM, op. cit., 1984, pp. 70-71 (cat. D), y p. 292 (cat. 219). Vid. también E. MACLAGAN, "An English alabaster altarpiece in the Victoria and Albert Museum", The Burlington Magazine for Connoisseurs, 36 (1920), pp. 53-65; P. WILLIAMSON, "Altarpiece with the Joys of the Virgin (the Swansea Altarpiece)", R. MARKS y P. WILLIAMSON (eds.), Gothic Art for England. 1400-1457, Londres, 2003, pp. 390-391 (n 275 ). 
Mayor como peregrino - con traje corto, zurrón en el costado derecho y bordón en la mano derecha- y San Andrés con la cruz aspada, respectivamente. Encima de María se encuentra San Pedro -tonsurado y con la llave- y encima de San Andrés San Judas con el barco. El resto de apóstoles no lleva su atributo, excepto el situado en el ángulo superior izquierdo, que debe ser San Bartolomé por el cuchillo que porta.

Una iconografía muy similar presenta Santiago en la Ascensión conservada en una colección privada de Brujas (Bélgica) ${ }^{57}$ : viste traje corto, con el zurrón en el costado derecho, un libro cerrado en la mano izquierda y el bordón en la derecha. Se sitúa en el extremo izquierdo de la escena, detrás de María, mientras que en el lado opuesto, detrás de San Juan, está San Judas Tadeo, con una barca en las manos. El resto de figuras carece de atributo, como en el panel custodiado en el Museo de Arte Sacro (Catharijneconvent) de Utrech, donde solo es posible identificar a los personajes del primer plano: San Andrés (cruz aspada), San Juan (palma), María (corona) y Santiago el Mayor como peregrino. Como en el ejemplo anterior, viste traje corto, lleva el zurrón en el costado derecho y sombrero caído a la espalda, sujeto al pecho por una gran correa.

La misma colocación presentan los principales protagonista de un panel conservado también en el Victoria \& Albert Museum (V\&A A.54-1935) 58 , que resulta excepcional por presentar la figura de Cristo resucitado -semidesnudo, mostrando las marcas de la Pasión y con una bandera sobre la cruz de palo largo- de cuerpo entero dentro de una mandorla, iconografía que se aparta de la representación tradicional de la Ascensión. La Virgen coronada y San Juan con la palma tienen tras de sí a Santiago el Mayor como peregrino y a San Andrés, respectivamente. El primero, descalzo y con traje corto, lleva un zurrón con una concha en su costado derecho y un sombrero -también decorado con una concha- sobre sus hombros, colgado del cuello, al tiempo que agarra un bordón con su mano derecha. San Andrés, por su parte, sujeta la habitual cruz en aspa. El resto de apóstoles no llevan atributos que permitan identificarlos.

El citado museo londinense posee también otro panel semejante (V\&A A.1441946) $)^{59}$, en el que Santiago vuelve a aparecer detrás de la Virgen María, caracterizado como peregrino al ir descalzo, vestir traje corto, con sombrero colgado a sus espalda, y sujetar el bordón en la mano derecha; falta por tanto el zurrón. Encima de él se encuentra San Pedro con la llave, emparejado con San Pablo -con la espada- que se sitúa encima de San Judas Tadeo, que, con la barca en las manos, está colocado detrás de San Juan Evangelista.

Para concluir este apartado, excepcional en cuanto a la disposición de los personajes $^{60}$, es el panel conservado en el Museo de Aquitania, en Burdeos ${ }^{61}\left(\mathrm{n}^{\mathrm{o}}\right.$ inventario 12

57 F. CHEETHAM, op. cit., 2003, p. 143 (nº 39) y lám. 95.

58 Mide 42,5 x 31,5 cm y se fecha en la segunda mitad del s. XV. F. CHEETHAM, op. cit., 1984, p. 294 (cat. 221).

59 Mide 41,6 x 24,7 cm y se fecha en la segunda mitad del s. XV. Ibid., p. 293 (cat. 220).

60 También resulta excepcional por la presencia de un apóstol barbado detrás del montículo desde el que Jesús ascendió a los cielos, que de ese modo se sitúa justo debajo de la parte inferior del cuerpo del Señor.

61 Mide 44 x $28 \mathrm{~cm}$ y se fecha entre 1380 y 1420, según la base de datos del Museo. http://collectionsmusees.bordeaux.fr/ 
572), ya que los apóstoles destacados en esta ocasión son San Pedro -a la izquierda y con la llave- y Santiago el Mayor -que, de forma extraordinaria, ha pasado al lado derecho-; es el único que va descalzo, lleva una especie de esclavina o manto corto sobre la túnica que le llega a la altura de las rodillas, y sujeta en la mano derecha el bordón, parcialmente mutilado, con puntera metálica en la parte inferior. Detrás de él aparece San Judas Tadeo con el barco mientras que detrás de San Pedro se encuentra San Bartolomé, que en lugar del cuchillo lleva su propia piel desollada, con su rostro casi pegado al suelo. San Juan Evangelista, por su parte, ha quedado relegado a la parte superior derecha de la composición; imberbe como siempre, lleva un libro y la palma.

El segundo bloque de este estudio se dedica a las representaciones exentas del apóstol Santiago como peregrino, aquellas en las que el "Hijo del Trueno" -como el evangelista Marcos denomina a Santiago el Mayor- no forma parte de ninguna escena narrativa. Son figuras exentas ${ }^{62}$, que integran algún apostolado o simplemente enmarcan escenas narrativas en diversos altares, en las que Santiago siempre aparece caracterizado como peregrino: descalzo, con traje largo, sombrero, bordón y zurrón en el costado, es decir, los atributos que permiten su identificación como caminante. Pero, además, incluyen una particularidad que podemos denominar "insular": junto a las tradicionales vieiras o conchas de peregrinos (Pecten Máximus y/o Pectem Jacobeus) que adornan su sombrero y su zurrón, en su túnica o manto -formando una especie de columna-aparecen unas caracolas o buccinos (Buccinum undatum $)^{63}$, que quizás deban ponerse en relación con las caracolas de Santiago que suelen llevar los peregrinos y su melodía, como se recoge en el Capítulo IV del Libro III del Codex Calixtinus ${ }^{64}$.

Entre las representaciones de Santiago con caracolas destaca la que forma parte de un Apostolado que, procedente de una iglesia de Zamora o de su provincia, ingresó en el Victoria \& Albert Museum en 1922 (V\&AA.150-1922) ${ }^{65}$. Cada uno de los apóstoles

62 Cheetham recoge 29 representaciones. F. CHEETHAM, op. cit., 2003, pp. 43-45.

63 Como señala Hildburgh, esas conchas o caracolas no sustituyen a las veneras habituales sino que las complementan. W.L. HILDBURGH, "Iconographical Peculiarities in English Medieval Alabaster Carvings", Folklore, 44, 1 (1933), pp. 123-150 (Part One) y 44, 2 (1933), pp. 123-150 (Part Two), esp. pp.130-143.

64 "Se cuenta que siempre que la melodía de la caracola de Santiago, que suelen llevar consigo los peregrinos, resuena en los oídos de las gentes, se aumenta en ellas la devoción de la fe, se rechazan lejos todas las insidias del enemigo; el fragor de las granizadas, la agitación de las borrascas, el ímpetu de la tempestad se suavizan en truenos de fiesta; los soplos de los vientos se contienen saludable y moderadamente; las fuerzas del aire se abaten". A. MORALEJO, C. TORRES y J. FEO (trads.), Liber Sancti Jacobi : Codex Calixtinus, Santiago de Compostela, 1951, p. 402.

65 Mide 45,4 x 14,2 cm y se fecha en el s. XV, posiblemente hacia 1425-1450. R.P. BEDFORD, "An English Set of the Twelve Apostles, in Alabaster", The Burlington Magazine for Connoisseurs, 42, 240 (1923), pp. 130-134; F. CHEETHAM, op. cit., 1984, p. 69 (cat. C) y p. 106 (cat. 35); P. WILLIAMSON, "Panneau avec représentation de Saint Jacques le Majeur", Santiago de Compostela. 1000 Ans de Pèlerinage Européen, Gante, 1985, p. 369 ( $\mathrm{n}^{\circ}$ 368), y "Santiago Peregrino, de una serie del Credo de los Apóstoles", Santiago, camino de Europa, op. cit., 1993, pp. 492-493 (n 170); J.I. MARTÍN BENITO, J.C. DE LA MATA GUERRA y F. REGUERAS GRANDE, Los Caminos de Santiago y la Iconografia Jacobea en el Norte de Zamora, Benavente, 1994, pp. 100-101; A. FRANCO MATA, "Un camino de ida y vuelta: Alabastros ingleses en España de regreso a Inglaterra. Referencias iconográficas", M. CABAÑAS BRAVO (coord.), El arte foráneo en España. Presencia e influencia, Madrid, 2005, pp. 237-253, esp. pp. 238-239; E. TOWNSEND, "The Twelve Apostles", R. MARKS y P. WILLIAMSON (eds.), op. cit, 2003, p. 385 (nº 267) afirma que quizás no se trate de un altar, como tradicionalmente se ha creído, sino que podría haber decorado el lateral de 
lleva una filacteria con su nombre y el texto del correspondiente artículo del Credo ${ }^{66}$, parcialmente conservado. La que lleva Santiago indica QUI CONC(e)PTUS EST DE SP(irit)O S(an)CTO NATUS EX MARIA VERG(ine) (Que fue concebido por obra del Espiritu Santo y nació de la Virgen María). Con barba y larga cabellera, viste túnica y manto y se cubre con un sombrero que luce una gran venera en su parte frontal. En el costado derecho lleva un pequeño zurrón, cruzado sobre el pecho, y el frente de su túnica se decora con seis caracolas, dispuestas como si se tratase de botones, a intervalos regulares, a la misma distancia aproximadamente unas de otras (Fig. 4).

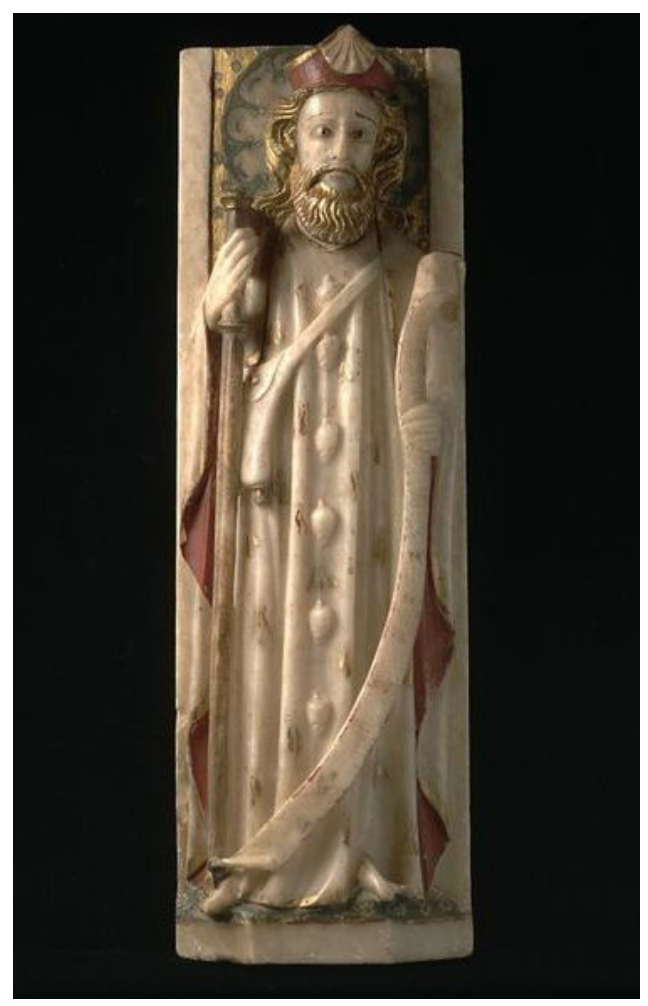

Fig. 4. Santiago Peregrino. Hacia 1425-1450. Alabastro policromado. 45,6 x 14,2 cm. Victoria \& Albert Museum, Londres.

El mismo número y tipo de conchas o caracolas lleva otra imagen del Apóstol que también forma parte de las colecciones del Victoria \& Albert Museum (V\&A A.89$1946)^{67}$. Es posible que fuese una imagen exenta de devoción privada, aunque tam-

un sepulcro de alabastro, como los de Sir William ap Thomas († 1445), en Avergavenny, Monmouth, y Sir Richard Vernon († 1451), en Tong, Shropshire.

66 A. FRANCO MATA, "El Doble Credo en el arte medieval hispánico", Boletín del Museo Arqueológico Nacional, XII, 1 y 2 (1995), pp. 119-136. Recoge abundante bibliografía al respecto.

67 Mide 54,2 x 19,8 cm y se fecha en el s. XV. Fue adquirida en París, y al parecer una obra muy similar, aunque obra de otro maestro o taller, fue vendida en Sotheby's en 1980. F. CHEETHAM, op. cit., 1984, p. 107 
bién podría haber formado parte de un altar. Con larga cabellera que le cae sobre los hombros, abundante barba y descalzo, Santiago se cubre la cabeza con un sombrero decorado con una concha o venera, al igual que el zurrón que lleva en su costado derecho, colgado del hombro contrario; sin embargo, su túnica aparece decorada por seis grandes caracolas dispuestas en vertical. Completa su atuendo de peregrino con el bordón -mutilado en su parte superior e inferior- que sujeta con su mano derecha, mientras que en la izquierda sostiene un libro cerrado, que luce un gran cierre.

Una iconografía semejante, aunque con un canon totalmente diferente, presenta otra pieza del Victoria \& Albert Museum (V\&A A.156-1946) ${ }^{68}$, procedente -como la anterior- de París ${ }^{69}$. Vestido con túnica y manto y descalzo, lleva un libro cerrado en la mano izquierda y, presumiblemente, sujetaría un bordón en la derecha, actualmente desaparecida. Además del citado bastón y de la concha que decora su sombrero, su condición de peregrino viene determinada por el zurrón que cuelga de su costado izquierdo y las cinco $^{70}$ caracolas que adornan su túnica, una de ellas parcialmente tapada por la correa del zurrón que cruza su pecho

También lleva dos caracolas adornando la parte inferior de su túnica otra imagen del apóstol Santiago conservada en el Victoria \& Albert Museum (V\&A A.461946 $)^{71}$. Como es habitual, va descalzo, luce barba, sujeta un libro cerrado en la mano izquierda y el bordón, parcialmente mutilado, en la derecha, actualmente desaparecida; en su costado izquierdo, prácticamente oculto por el manto que le cubre hasta las rodillas, lleva una pequeña bolsa que -se supone-colgaría de su hombro derecho. La originalidad de esta pieza radica en que Santiago presenta la cabeza descubierta, aunque lleva un sombrero, sujeto al cuello por una correa y apoyado sobre su hombro derecho.

Otras piezas semejantes -en las que Santiago lleva esas extrañas caracolas- se conservan todavía en instituciones religiosas que quizás fueran su destino original: iglesia de Ysaac la Tourete, en Puy-de-Dôme; iglesia de Nouâtre e iglesia parroquial de San Pedro de Marray, ambas en Indre-et-Loire, iglesia de San Pedro de Juignettes, en Eure, iglesia parroquial de San Martín de Rethoville, en Manche... ${ }^{72}$

Junto a esas imágenes caracterizadas por la presencia de las caracolas, dentro de la producción inglesa de alabastros podemos encontrar otras imágenes del apóstol Santiago identificado como peregrino de acuerdo con su iconografía más tradicional o convencional, es decir, tal y como es frecuentemente representado en el arte europeo de los siglos XIV y XV.

\footnotetext{
(cat. 36), y op. cit., 2003, p. 43 (cat. 8) y lám. 48.

68 Mide 41 x $12 \mathrm{~cm}$ y se fecha en el s. XV. F. CHEETHAM, op. cit., 1984, p. 103 (cat. 32).

69 Fue adquirida allí en 1928 por W.L. Hildburgh, lo cual no quiere decir que ese fuera su primitivo destino.

70 En las otras imágenes en que Santiago lleva ese tipo de caracolas, el número de estas asciende a seis. En esta ocasión, el espacio existente entre la primera y la tercera, empezando por abajo, es notablemente más grande que el resto, por lo que quizás hubo una sexta caracola, actualmente desaparecida, o al menos se planteó su existencia. No podemos confirmarlo, pero podría ser un aspecto interesante a tener en cuenta, independientemente de que ese número, el seis, pueda tener un valor simbólico o no.

71 Mide 42 x 13,2 cm y se fecha en el s. XV. F. CHEETHAM, op. cit., 1984, p. 103 (cat. 32).

72 Fichas técnicas, muy básicas, e imágenes accesibles a través de la base de datos Mobilier-Palissy: http:// www.culture.gouv.fr/culture/inventai/patrimoine/
} 


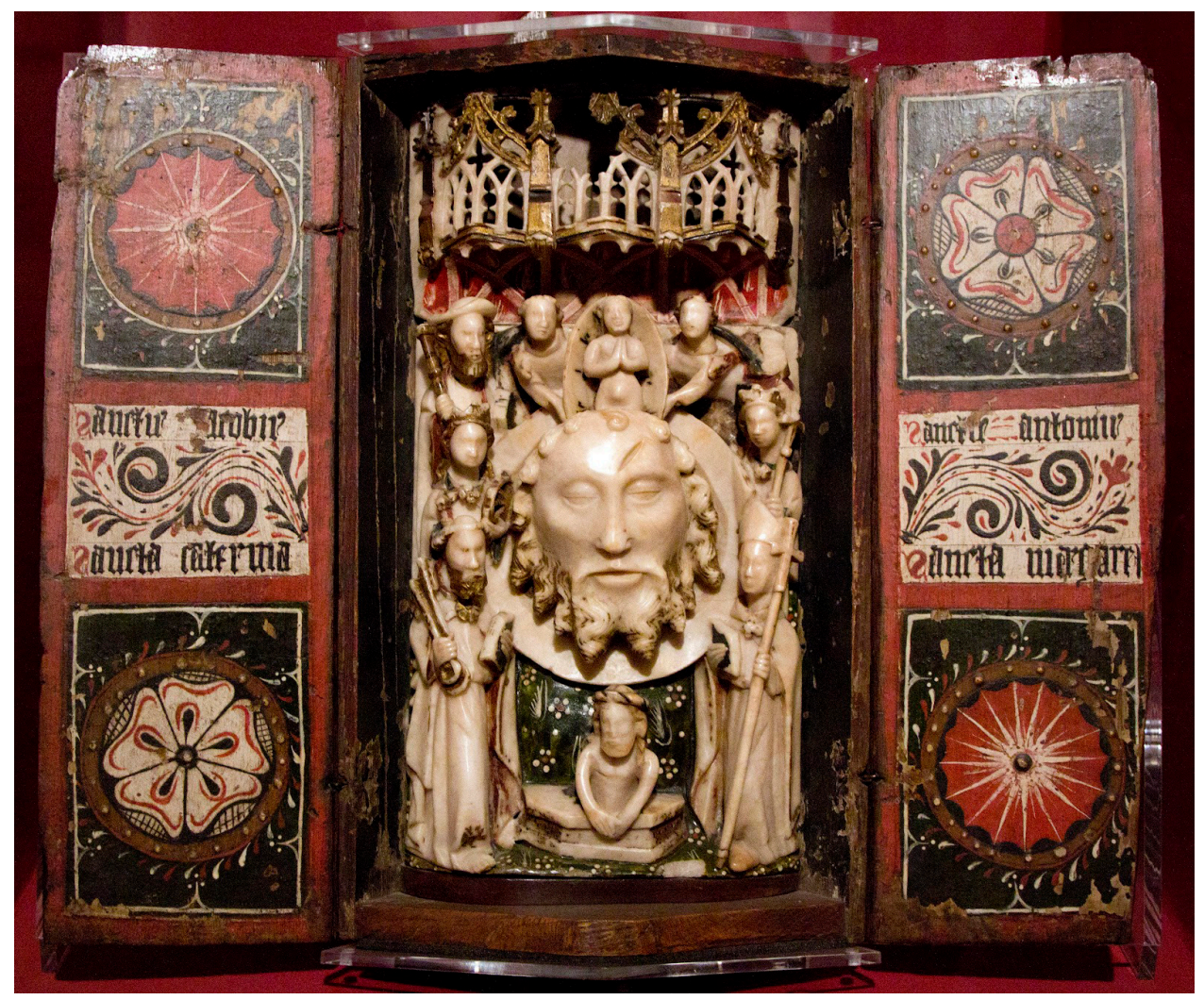

Fig. 5. Cabeza de San Juan Bautista con santos (Santiago Peregrino). Hacia 1470-1485. Alabastro policromado. 47,8 x 25,5 cm (con marco). The Burrell Collection, Glasgow Museums.

Sin salir de las colecciones del Victoria \& Albert Museum, cabe destacar una pieza que presenta a los dos hijos del Zebedeo, cada uno con su correspondiente filacteria, y que indudablemente debió de formar parte de un altar con la representación del Apostolado (V\&A A.22-1946) ${ }^{73}$. Santiago, en el lado izquierdo, viste larga túnica y manto y se cubre la cabeza con un sombrero de ala vuelta decorado en la parte frontal con una concha. Luce barba partida, larga cabellera hasta los hombros y está descalzo. Con el brazo izquierdo sujeta el bastón de peregrino -con pomo en la parte superior y puntera metálica en la inferior- al tiempo que con el dedo índice de esa mano señala hacia la filacteria que sostiene con la mano derecha y que se despliega verticalmente desde su rostro hasta más abajo de sus rodillas. La inscripción actualmente desaparecida recogería el artículo del Credo que tradicionalmente se le atribuye "Qui conceptus es". Su hermano San Juan, también descalzo e imberbe de acuerdo con su iconografía tradicional, sostiene otra filacteria semejante con su mano

73 Mide 40 x 28,2 cm y se fecha en el s. XV. F. CHEETHAM, op. cit., 1984, p. 108 (cat. 37). 
izquierda mientras que en la derecha lleva un cáliz con un pequeño dragón, uno de sus principales atributos, alusivo a la copa de veneno que le dieron a beber.

Un último ejemplar de las colecciones del Victoria \& Albert Museum muestra al apóstol Santiago como peregrino situado bajo una especie de pequeño dosel (V\&A A.183-1946) ${ }^{74}$. Viste una larga túnica hasta el suelo que deja ver sus pies descalzos, luce barba corta y larga cabellera, y se cubre la cabeza -levemente girada hacia su izquierda- con un sombrero de ala levantada ${ }^{75}$. Lleva un zurrón colgado de su hombro derecho y en la mano izquierda sujeta un libro cerrado, en posición vertical. Le falta el brazo derecho, pero el arranque del antebrazo sugiere que probablemente lo tendría extendido y llevaría el tradicional bordón de peregrino.

El último apartado dedicado a la iconografía jacobea en los alabastros ingleses se refiere a la presencia del Apóstol Santiago como Peregrino en un tipo muy particular de piezas, las llamadas St John's heads (cabezas de San Juan) ${ }^{76}$. Generalmente la cabeza del santo está flanqueada por las figuras de San Pedro y San Guillermo de York, o bien por Santo Tomás Becket, a los que se pueden incorporar otros santos, entre los que se encuentra Santiago el Mayor caracterizado como peregrino ${ }^{77}$, con sombrero de ala ancha, bordón en una mano y libro cerrado en la otra. El Apóstol no aparece en ninguna de las cabezas de San Juan conservadas en España ${ }^{78}$, pero sí lo vemos, por ejemplo, en varias piezas conservadas en el V\&A Museum ${ }^{79} \mathrm{y}$ en la Colección Burrell ${ }^{80}$ de Glasgow. En las tres placas del museo londinense Santiago aparece en un segundo plano, en la zona superior de la composición, en el lado izquierdo encima de San Pedro en dos de ellas ${ }^{81}$ y en el lado derecho, sobre Santo Tomás Becket, en la restante. La pieza de la Colección Burrell, por su parte, es más compleja ${ }^{82}$ al incluir

74 Mide 25,1 x 10,2 cm y se fecha en el s. XV. Ibid., p. 104 (cat. 33).

75 Cheetham ( ibid.) señala la semejanza de ese sombrero con el que luce el apóstol en una pieza conservada en el Santa Barbara Museum of Art de California, imagen que no he podido encontrar o ver.

76 W.H. HOPE, “On the sculptured alabaster tablets called Saint John's Heads", Archeologia, LII (1890), pp. 669-708; F. CHEETHAM, op. cit., 1984, pp. 317-332, y op. cit., 2003, pp. 156-160. En esta última publicación recoge 97 alabastros con esta temática, pero no incluye algunas piezas conservadas en España, como la del Museo Massó en Pontevedra o la del Convento del Espíritu Santo en Jerez de la Frontera. Para estas obras vid. T.C. MOURE PENA, "Caput Sancti Ihoanis Baptiste in disco en un alabastro gótico inglés de la antigua Colección Massó”, Archivo Español de Arte, LXXVII, 307 (2004), pp. 319-326; C. MARTÍN MOCHALES, "Restauración del relieve en alabastro procedente del Asilo de San José, Jerez de la Frontera", Revista de Historia de Jerez, 11-12 (2005-2006), pp. 197-219. Tampoco los recoge A. FRANCO MATA, op cit. (1999).

77 En estos casos no aparecen ya las caracolas que frecuentemente luce el Apóstol en otras placas de alabastro.

78 Capilla de los Gaitán de Ayala, en Markina-Xemein, Bizkaia (actualmente en paradero desconocido); Museo Nacional de Artes Decorativas, Madrid; Museo Massó, Bueu, Pontevedra; Colección Manrique de Lara, Las Palmas de Gran Canaria; Convento del Espíritu Santo, Jerez de la Frontera, Cádiz.

79 A.127-1946, que mide 32,9 x 20,8 cm; A.127B-1946 (29 x 18,7 cm) y A.159-1946 (26,4 x 19,1 cm). Todas ellas se fechan a fines del s. XV. F. CHEETHAM, op. cit., 1984, pp. 329 (cat. 253), 331 (cat. 255) y 332 (cat. 256).

80 Mide 42,7 x 53,3 cm (con las puertas abiertas) y se fecha hacia 1470-1485. Ibid., p. 54 (fig. 33 ); P. WILLIAMSON, "Tabernacle with Head of St John the Baptist and saints", R. MARKS y P. WILLIAMSON (eds.), op. cit., 2003, p. 341 (n 219).

81 A.127-1946 y A.127B-1946.

82 Forma parte de un tríptico con las puertas de madera pintadas. 
a seis santos flanqueando la cabeza del Precursor. Además de San Pedro y San Guillermo de York, encontramos a Santa Catalina y Santa Margarita, y a San Antonio y Santiago, este en el ángulo superior izquierdo y portando sus atributos característicos (Fig. 5).

Como conclusión, podemos señalar que el apóstol Santiago el Mayor -siempre como peregrino- es uno de los santos más representados en los alabastros medievales ingleses, prueba de la gran devoción de la que era objeto, y que sus representaciones ofrecen, en ocasiones, interesantes particularidades iconográficas. 